\title{
Life Disruptions for Midlife and Older Adults With High Out-of-Pocket Health Expenditures
}

David Grande, $M D, M P A^{1,2}$

Frances K. Barg, $P b D^{3}$

Sarab Jobnson, $B A^{4}$

Carolyn C. Cannuscio, $S_{C} D^{2,3,5}$

'Department of Medicine, University of Pennsylvania, Philadelphia, Pennsylvania

${ }^{2}$ Leonard Davis Institute of Health Economics, University of Pennsylvania, Philadelphia, Pennsylvania

${ }^{3}$ Department of Family and Community Health, University of Pennsylvania, Philadelphia, Pennsylvania

${ }^{4}$ Perelman School of Medicine, University of Pennsylvania, Philadelphia, Pennsylvania

${ }^{5}$ Center for Health Equity Research and Promotion, Philadelphia VA Medical Center, Philadelphia, Pennsylvania

Conflicts of interest: David Grande reports serving as an expert witness on bebalf of the State of Vermont, receiving honoraria from the Johns Hopkins University CME Program, and a prior consultancy with the National Nursing Centers Consortium. He previously served as a board member of the National Pbysicians Alliance and is currently a board member of Healthy Pbiladelphia, both uncompensated positions. The other authors report no conflicts of interest.

\section{CORRESPONDING AUTHOR}

David Grande, MD, MPA

Division of Internal Medicine

University of Pennsylvania

3641 Locust Walk - Room 407

Philadelphia, PA 19104

dgrande@wharton.upenn.edu

\begin{abstract}
PURPOSE Out-of-pocket cost sharing for health care expenses is a growing burden. Prior research has emphasized the medical consequences of cost sharing. This study investigates the range of social, medical, financial, and sometimes legal disruptions from high out-of-pocket health expenses.
\end{abstract}

METHODS We conducted open-ended, semistructured interviews with 33 insured patients (two-thirds covered by Medicare). All had chronic illnesses and sought philanthropic financial assistance.

RESULTS We found that high levels of cost sharing precipitated considerable anxiety and substantial debt problems, as well as disruptions of medical care. Participants described various borrowing strategies (eg, credit cards), legal problems (eg, debt collections), and threats to their nonmedical household budgets (eg, food, housing). Participants described explicit and rank-ordered strategies for coping with new medical expenses. Participants understood their health benefits with exceptional detail but described considerable anxiety about changes to those benefits that could easily disrupt carefully managed household budgets. Benefit designs that resulted in large a variations in financial liability from month to month (eg, large deductibles or coverage gaps) imposed considerable financial challenges.

CONCLUSIONS As health care cost sharing grows, policy makers will need to consider the consequences of high cost sharing for families facing strained household budgets. Although the generosity of health insurance is important, continuity of benefits and month-to-month stability of financial liability are also important and may be undervalued in policy discussions.

Ann Fam Med 2013;11:37-42. doi:10.1370/afm.1444

\section{INTRODUCTION}

$\Lambda$ merican families are contributing a growing fraction of their personal income to health care. ${ }^{1-3}$ From 1999 to 2007, health insurance premiums increased more than 4 times faster than wages. ${ }^{4,5}$ Benefits also have become less comprehensive..$^{1,4,6-8}$ These cost pressures lead families to make financial trade-offs within their household budgets in response to health care needs. Little is known about the choices families make and how they make them. In this study, we investigate the range of social, medical, financial, and sometimes legal disruptions from high out-of-pocket health expenses. We refer to these broad effects as life disruptions.

The literature examining financial burden from health care focuses on 2 major areas. First, several studies have examined trends in the numbers of individuals and families facing a great financial burden from health care. These studies generally have shown that a large and growing percentage of Americans are experiencing financial challenges attributable to health care. ${ }^{1,2,7,9}$ Second, other studies have examined the extent to which high levels of cost sharing and financial burdens translate into decreased use of 
necessary health services, such as ambulatory visits or prescription drugs. ${ }^{10-12}$

Fewer studies have examined how financial stress from health care may affect overall household finances. Himmelstein and colleagues have shown that approximately one-half of personal bankruptcies are related to medical spending. ${ }^{13,14}$ Several other authors have reported basic measures of financial stress, such as difficulty paying for other expenses attributable to health care. ${ }^{15,16}$ We are not aware, however, of studies that have examined the scope and magnitude of life disruptions from high-cost medical spending in a household. Given that financial stress itself is linked to worse health, the role of health insurance in creating economic security is itself important for health. ${ }^{17}$ Our study makes a unique contribution by examining the complex ways in which great amounts of out-of-pocket spending for health care affects other important household domains.

Prior studies have shown that less insurance (ie, less generous benefits) is associated with greater financial distress. ${ }^{16,18}$ Little is known about how health insurance shapes household budgets and its role in smoothing risk, a process that distributes financial liability for health care evenly over time and minimizes financial shocks. ${ }^{19}$ What are the medical, financial, and social challenges associated with medical expenses? And how do patients navigate complex financial decisions tied to their own health?

In our study, we examined these questions in a population of midlife and older adults facing serious medical illness and high-cost out-of-pocket medical spending. All participants sought financial assistance from a foundation. The answers to these questions foreshadow how families may fare as insurance coverage becomes more widely available but potentially less comprehensive under the Affordable Care Act (ACA).

\section{METHODS}

We conducted open-ended, semistructured interviews with individuals who applied to the HealthWell Foundation, Gaithersburg, Maryland, for financial assistance to help pay for the costs of their illness. The HealthWell Foundation is a nonprofit organization that assists insured chronically ill individuals with copayments, coinsurance, and health insurance premiums (http://www.healthwellfoundation.org/). The foundation receives financial contributions from individual and corporate donors. Most applicants are covered by Medicare and are frequently seeking copayment assistance; however, privately insured individuals also apply for similar reasons, as well as for assistance with insurance premiums. We chose this population to understand the nature of financial distress among a population with a chronic illness facing health care cost barriers. The study was approved by the Institutional Review Board at the University of Pennsylvania.

\section{Participants}

A purposive sampling method was used to identify potential participants among patients who applied to the HealthWell Foundation for financial assistance who were older than 18 years, were insured, and had 1 of 32 serious medical conditions. Eligible participants were contacted once by mail or e-mail and invited to participate. If they agreed, they were contacted by either the principal investigator (D.G.) or a research assistant, who obtained verbal consent to participate and then interviewed the respondent over the telephone. Participants were offered a $\$ 25$ gift card for interview completion.

\section{Data Collection}

Interviews were conducted over the telephone. The interview guide consisted of 17 open-ended questions that elicited information about general and specific illness-related financial challenges. We specifically probed for challenges in the domains of housing, food, utilities, savings, and borrowing, as well as health care expenses. We offered participants the opportunity to elaborate within each of these domains. The interview guide (Supplemental Appendix, available at http://ann fammed.org/content/11/1/37/suppl/DC1) included language to reduce stigma associated with financial distress, given that all participants sought financial help. Interviews generally lasted 20 to 35 minutes and were audio-recorded with the respondents' permission, transcribed, and prepared for analysis. The study team met regularly to debrief the content of interviews. We agreed after 33 interviews that saturation had been reached, and recruitment was terminated.

\section{Data Analysis}

De-identified transcripts were entered into QSR NVivo 9.0 (QSR International) for analysis. We used a modified grounded theory approach, ${ }^{20}$ coding the data using an a priori set of codes based upon our original study question, as well as a list of codes that emerged from a close reading of the data. Using the constant comparison method, ${ }^{21}$ we moved iteratively between codes and text. A subset of the data was coded by 2 coders, and any disagreements in coding were resolved by consensus. After the data were coded, we searched the key codes for themes and patterns within each theme. Key themes were discussed by the study team.

\section{RESULTS}

One hundred fifteen applicants for financial assistance from the HealthWell Foundation were contacted dur- 
ing the period July 1, 2010, and September 20, 2010, and 33 agreed to participate (30\% response rate). The participants tended to be of older age, reside in metropolitan areas, and have low to moderate income. Most participants were insured through Medicare (Table 1).

Four issues figured prominently. First, the structure of health insurance-especially gaps in coverage, such as the Medicare Part D "doughnut hole"—-powerfully affected financial well-being. Second, financial stress and debt from medical expenditures had a strong influence on day-to-day personal, financial, and medical decision making. Third, participants turned to family and other sources to help manage the costs of their illnesses, which resulted in financial, emotional, and social challenges for all family members. Fourth, participants managed high out-of-pocket health care costs using a range of strategies that were potentially disruptive to their medical care.

\section{Influence of Health Insurance Structure on Financial Stress}

All of the participants were insured, and all reported that medical expenses considerably exceeded their insurance coverage. In describing their insurance benefits, respondents were often precise regarding the nature and extent of their benefits, eg, the remaining

\begin{tabular}{|c|c|c|c|}
\hline Characteristic & No. (\%) & Characteristic & No. (\%) \\
\hline Age, y & & Geography & \\
\hline $21-40$ & $3(9)$ & Rural & $5(15)$ \\
\hline $41-60$ & $12(36)$ & Nonrural & $28(85)$ \\
\hline $61-70$ & $12(36)$ & Region & \\
\hline $71-95$ & $6(18)$ & Midwest & $4(12)$ \\
\hline Race & & Northeast & $7(21)$ \\
\hline African American & $4(12)$ & South & $13(39)$ \\
\hline White & $26(79)$ & West & $9(27)$ \\
\hline Missing & $3(9)$ & Health condition & \\
\hline Ethnicity & & prompting application & \\
\hline Not Hispanic & $29(88)$ & for assistance & \\
\hline Hispanic & $3(9)$ & Arrhythmia & $1(3)$ \\
\hline Missing & $1(3)$ & Arthritis & $10(30)$ \\
\hline Income & & Asthma & $2(6)$ \\
\hline$<\$ 20,000$ & $13(39)$ & Cancer & $13(39)$ \\
\hline$\$ 20,000-\$ 40,000$ & $15(46)$ & Hepatitis C & $2(6)$ \\
\hline$\$ 40,000-\$ 60,000$ & $4(12)$ & Kidney/renal disease & $5(15)$ \\
\hline Missing & $1(3)$ & Insurance type & \\
\hline Education & & Cobra & $4(12)$ \\
\hline High school & $20(61)$ & Employer & $6(18)$ \\
\hline Some college & $3(9)$ & Medicaid & $1(3)$ \\
\hline College graduate & $6(18)$ & Medicare & $22(67)$ \\
\hline Graduate school & $4(12)$ & & \\
\hline
\end{tabular}

Note. The number of participants covered by Medicare exceeded the number older than 65 years, suggesting that the sample includes chronically disabled individuals who were younger than 65 years. duration of COBRA coverage, the dollar amounts of their deductibles, and the precise copayments. Precise reporting was frequent ("This month I had to pay because I had $\$ 191$ dollars left on my prescription insurance, I had to pay $\$ 291$ dollars.")

When participants reported confusion regarding their health care coverage, that confusion typically stemmed from benefit changes. Participants described how they had come to marginally understand, and sometimes even accommodate, the limits of their health plans, but changes in deductibles, premiums, and copayments upset their carefully calibrated household budgets.

Costs of prescription medications were uniformly challenging for participants, both in terms of individual copayments and total monthly cash expenditures.

Participants often reported their monthly prescription costs to the dollar amount. This acute financial awareness weighed heavily on participants, especially during their tenure in the Medicare doughnut hole - the Part D pharmacy benefit coverage gap. The doughnut hole presented a vexing challenge, because each year promised a new opportunity to hit the coverage gap. One participant referred to this gap as going into "the black hole." Some described the challenges of coinsurance (paying a proportion of costs) vs fixed-dollar copayments. Prices are variable; seemingly modest coinsurance can require high out-of-pocket spending on expensive pharmaceuticals. One respondent described how "that 20\% can kill you."

\section{Management of Financial Stress and Medical Debt}

Respondents spoke of difficulty paying their household bills because of their medical expenses. Financial coping decisions often appeared to have been made strategically rather than haphazardly. To pay medical bills, participants commonly described an explicit ranking of bill-paying priorities, often beginning with housing costs and involving compromises on heating, transportation, and food. As one participant described:

Number 1's the mortgage... that gets paid first. And number 2, my large bill's the COBRA premium. And then number 3, I give my daughter $\$ 400$ to $\$ 500$ a month to go to [college].... I couldn't heat the house.

Some respondents took proactive austerity measures to forestall financial crises, including moving to lower cost housing or taking out a home equity loan, and in one case having newer cars "voluntarily repoed" in favor of a "junker" car. Another participant 
explained her compromise on food: "I meet all my bills. If anything I have to budge on, it's food...that's the one that gets whatever's left.... You get to figure out how to be creative with food." Less commonly, participants described reactive coping strategies_-eg, being unable to pay housing bills and therefore facing eviction, mortgage default, or foreclosure.

Overall, medical expenses seemed to be a source of substantial stress among respondents. Participants used stark metaphors of medical expenses hitting or kicking them. They infrequently used hopeful metaphors ("making ends meet") to describe their financial situations. More often, participants used metaphors that evoked struggle and death ("went to hell," "signed my death warrant," "going down in flames.")

Several participants reported using their credit cards to compensate for underinsurance. Although multiple participants reported trying to keep up with credit card bills, others had given up entirely on repaying the debt. Some respondents reported coping by avoiding bills, creditors, and discussion of financial matters, even with their spouses. Importantly, several participants were engaged in legal matters as a result of their unpaid medical debts. Others feared for the longer-term implications of their current financial hardship: "So it's going to get harder and...we have really great credit. I hate to ruin that, but it looks like it might get ruined if we can't afford to pay all these high medical bills."

\section{Family-Level Impact of High Out-of-Pocket Health Spending}

The family-level impact of illness and associated health care costs was evident throughout all interviews. Multiple participants reflected a degree of reticence and wounded pride regarding asking family members for cash assistance. Often, participants described getting bits of financial support from many people to distribute the burden. In some cases, this money was offered forthrightly by family members, but in other cases participants described having no choice but to ask for help. One person bluntly described how he borrowed money, but that the people who loaned it will never see it again: "What we did was borrow from friends and family, probably about $\$ 30,000$ dollars, and they'll never see it because it will never come back."

In deciding whether to ask for family help, participants considered the other stressors operating within their family networks. For example, participants noted family members' work responsibilities and geographic distance as factors that limited their ability to provide practical support. One participant noted with a degree of guilt that his son was at war in Iraq, sending money back to provide for his father's medical care. Another participant explained how he resisted asking for help because he didn't think of himself as a good investment. He said, "I just don't want a bunch of people putting money...into me if I'm not going to make it." Several participants reported having to move in with family members (either children or parents) because they could no longer afford living alone.

\section{Disruption of Medical Care and the Doctor- Patient Relationship}

Delaying medical care was a common financial coping strategy, as in the case of one participant who "wouldn't go to the doctor unless I just could not stand...the pain." In some cases, participants described anxiety and regret associated with foregoing needed but prohibitively expensive treatments

It's scary because when you know you've had colon cancer and your... stool starts changing..., then you start getting scared again.... And you know that every month you put this off...you're really hurting yourself.

Participants understood the potential adverse health consequences of care delays or nonadherence to treatment, but they did not see a viable alternative. Costs, rather than unwillingness to comply with recommended treatment, weighed heavily in decisions to delay or avoid recommended care. These self-rationing decisions were often made without a doctor's input, although one participant described a negotiation she had with her physician regarding when to start chemotherapy:

After test results, he wanted to start...chemo. And...there was no way I could start paying for that. So he put it off. He said how much time do you need to come up with the money? And I said 3 months... He wasn't happy about that, but I just don't have the money.

Participants reported willingness to suffer to avoid medical expenditures. For the following participant, insurance covered $\$ 900$ of the $\$ 1,200$ cost for a 30 -day supply of an antiemetic to accompany his cancer chemotherapy: "I couldn't take it. I can't afford it. The copay was even too hard to handle... I said, you know what, I'd rather be sick."

To comply with unaffordable treatments, some participants sought assistance from physicians, most commonly in the form of medication samples.

I skipped the Arimidex from November until March because I couldn't afford the copay. I could see the handwriting on the wall at the start of the heating season. So then when I went to my oncologist in March, I told him that I had not been taking the Arimidex since November, and he generously provided me with Arimidex.

Other participants sought low-cost or uncompensated medical consultations, particularly through tele- 
phone contact with physicians. Participants recognized that doctors were providing this type of care "out of the kindness of their heart" and observed that they were more likely to receive "free" advice from their primary care physicians than from specialists.

\section{DISCUSSION}

The participants in our study, all of whom faced major chronic illnesses and most of whom were covered by Medicare, provided several insights on how insured patients cope with the financial stresses associated with high out-of-pocket spending. First, much to our surprise, participants were extremely knowledgeable about their benefits. Even so, they struggled with benefit changes. With little cushion in their household budgets, changes to insurance benefits easily overwhelmed carefully developed coping strategies. Another important and new finding is insurance benefits that varied financial liability from month to month were particularly troublesome. Participants often turned to extreme measures, including credit cards, to cope with and smooth high medical expenses. Participants were reluctant to ask for financial help from friends and family, often owing to feelings of shame or guilt. Finally, health care costs and financial struggles were rarely part of an explicit discussion with doctors and at times altered from whom they sought care.

There are several important implications to these findings. This study showed that during the course of an illness patients actively learn about and attempt to manage their insurance benefits. The current emphasis on complex insurance design (eg, tiered formularies) will likely make benefits more volatile and therefore difficult to accommodate in financially stressed households. As benefit designs require more cost sharing, many low- and moderate-income patients with chronic conditions will experience the life disruptions described by the patients in our study, including substantial financial trade-offs with household necessities, stress on familial relationships, and medical nonadherence. More patients may also start turning to undesirable sources of financing for medical care, such as credit cards. Finally, with the proliferation of high-deductible health plans, it is assumed that patients and doctors will engage in discussions to make decisions that are both medically sound and cost conscious. Participants in our study infrequently discussed costs with their physicians and therefore decided unilaterally which medical tests and treatments were essential and which were too costly to pursue.

The ACA will lower cost barriers for many previously uninsured Americans, but it will not likely reverse the overall trend of increasing financial liability for patients. For Medicare enrollees (a majority of our sample), the ACA will reduce financial stress by closing (by 2020) the particularly challenging coverage gap (doughnut hole) in Medicare Part D, which was noted by nearly all of our participants as one of the leading causes of their financial difficulties. ${ }^{22}$ Other structural aspects of Medicare benefits will not change under the ACA. For the remainder of the population, the ACA will have mixed effects on cost sharing. Individuals with an income of less than $400 \%$ of the federal poverty limit will be eligible for some protection through costsharing subsidies that limit deductibles, copayments, and out-of-pocket maximums. Individuals who use health services frequently, however, will still be liable for considerable out-of-pocket costs. For example, a single adult earning $\$ 30,000$ (midpoint of the modal income range in our sample), would be liable for up to $\$ 3,000$ in cost sharing annually. ${ }^{23,24}$ There would be no assurances that this spending would be evenly distributed during the course of a year. Our research showed that many patients have limited flexibility in their monthly budgets to accommodate episodic increases in health care expenditures. Thus, even small changes in monthly financial liability can be disruptive.

Our study has several limitations. First, participants were recruited from a patient financial assistance program. They are not representative of all patients with a chronic medical illness or all patients with financial concerns. Patients who seek out financial assistance from a philanthropic organization may have different coping mechanisms and be more resourceful than other financially stressed patients. Given that the program identifies patients facing cost-related barriers, however, we chose this population to better understand the nature of financial distress among this important group. Second, although our sample included privately insured individuals, our results may be most applicable to the specific benefit structure of Medicare, from which most of our sample received their coverage. The heterogeneity of benefit structures within private insurance plans may introduce different challenges. Third, as a qualitative study, we are not able to quantify the prevalence of various life disruptions or coping strategies; instead, we emphasize the range of experiences. The experiences of our participants are likely to be shared by many other insured patients facing high out-of-pocket costs. In addition, our qualitative approach has the strength of allowing greater exploration of the complex behavioral decisions facing patients such as those in our study.

Given the complexities of health care financing, the role that primary care doctors can play in helping their patients is challenging but important. Physicians need training and tested strategies to screen for and discuss patients' financial stress. Although physicians strongly support intervening on unmet social needs, ${ }^{25}$ it is diffi- 
cult to expect physicians to solve this issue alone. New models are needed that link physician practices with social services and other resources such as financial counseling. Health Leads is an example of a program that embeds volunteers in primary care clinics to provide this kind of support to patients. ${ }^{26} \mathrm{New}$ models and programs need to be developed that can work across different populations and practice settings to support comprehensive, patient-centered primary care.

\section{To read or post commentaries in response to this article, see it} online at http://www.annfammed.org/content/11/1/37.

Key words: insurance benefits; cost sharing; health care financing

Submitted February 10, 2012; submitted, revised, June 26, 2012; accepted July 12, 2012.

Author contributions: Dr Grande had full access to all the data in the study and takes responsibility for the integrity of the data and the accuracy of the data analysis.

Funding support: This study was supported by the HealthWell Foundation, Gaithersburg, Maryland.

Disclaimer: The funder had no role in the design and conduct of the study; collection, management, analysis, and interpretation of the data; or preparation, review, or approval of the manuscript.

Acknowledgment: The authors thank Shimrit Keddem and Katie Kellom for their assistance with analyzing the data, and Suzanne Miller for her guidance.

\section{References}

1. Cunningham P. Chronic Burdens: The Persistently High Out-of-Pocket Health Care Expenses Faced by Many Americans with Chronic Conditions. Vol 63. New York, NY: The Commonwealth Fund; 2009. http://www.commonwealthfund.org/Publications/Issue-Briefs/2009/ Jul/Chronic-Burdens-The-Persistently-High-Out-of-Pocket-HealthCare-Expenses-Faced-by-Many-Americans. aspx\#citation.

2. Collins S, Kriss J, Doty M, Rustgi S. Losing Ground: How the Loss of Adequate Health Insurance Is Burdening Working Families: Findings from the Commonwealth Fund Bienniel Health Insurance Surveys, 2001-2007. New York, NY: The Commonwealth Fund; 2008. http:// www.commonwealthfund.org/Publications/Fund-Reports/2008/Aug/ Losing-Ground--How-the-Loss-of-Adequate-Health-Insurance-IsBurdening-Working-Families--8212-Finding.aspx.

3. Polsky D, Grande D. The burden of health care costs for working families-implications for reform. N Engl J Med. 2009;361(5):437-439.

4. Claxton G, DiJulio B, Finder B, et al. Employer Health Benefits: 2007 Annual Survey. Menlo Park, CA: Kaiser Family Foundation and Health Research and Educational Trust; 2007. http://www.kff.org/ insurance/7672/upload/76723.pdf.

5. Ginsburg P. High and rising health care costs: demystifying U.S. health care spending. Research Synthesis Report No 16. Princeton, NJ: Robert Wood Johnson Foundation; 2008. http://www.rwjf.org/ content/dam/farm/reports/reports/2008/rwjf32703.

6. Banthin JS, Cunningham P, Bernard DM. Financial burden of health care, 2001-2004. Health Aff (Millwood). 2008;27(1):188-195.

7. Schoen C, Collins SR, Kriss JL, Doty MM. How many are underinsured? Trends among U.S. adults, 2003 and 2007. Health Aff (Millwood). 2008;27(4):w298-w309.

8. Claxton G, Dijulio B, Whitmore H, et al. Health benefits in 2010: premiums rise modestly, workers pay more toward coverage. Health Aff (Millwood). 2010;29(10):1942-1950.
9. Cunningham PJ. Explaining the increase in family financial pressures from medical bills between 2003 and 2007: do affordability thresholds change over time? Med Care Res Rev. 2011;68(3):352-366.

10. Rahimi AR, Spertus JA, Reid KJ, Bernheim SM, Krumholz HM. Financial barriers to health care and outcomes after acute myocardial infarction. JAMA. 2007;297(10):1063-1072.

11. Andrulis DP. Access to care is the centerpiece in the elimination of socioeconomic disparities in health. Ann Intern Med. 1998;129(5): 412-416.

12. Weissman JS, Stern R, Fielding SL, Epstein AM. Delayed access to health care: risk factors, reasons, and consequences. Ann Intern Med. 1991;114(4):325-331.

13. Himmelstein DU, Thorne D, Warren E, Woolhandler S. Medical bankruptcy in the United States, 2007: results of a national study. Am J Med. 2009;122(8):741-746.

14. Himmelstein DU, Warren E, Thorne D, Woolhandler S. Illness and injury as contributors to bankruptcy. Health Aff (Millwood). 2005;Suppl Web Exclusives:W5-63-W/5-73.

15. Cunningham P, Miller C, Cassil A. Living on the Edge: Health Care Expenses Strain Family Budgets. HSC Research Brief No 10. Washington DC: Center for Studying Health System Change; 2008. http:// hschange.org/CONTENT/1034/1034.pdf.

16. Galbraith AA, Ross-Degnan D, Soumerai SB, Rosenthal MB, Gay $C$, Lieu TA. Nearly half of families in high-deductible health plans whose members have chronic conditions face substantial financial burden. Health Aff (Millwood). 2011;30(2):322-331.

17. Alley DE, Soldo BJ, Pagán JA, et al. Material resources and population health: disadvantages in health care, housing, and food among adults over 50 years of age. Am J Public Health. 2009;99(Suppl 3): S693-S701.

18. Madden JM, Graves AJ, Zhang F, et al. Cost-related medication nonadherence and spending on basic needs following implementation of Medicare Part D. JAMA. 2008;299(16):1922-1928.

19. Finkelstein A, Taubman S, Wright B, et al. The Oregon Health Insurance Experiment: Evidence From the First Year. Princeton, NJ: The Robert Woods Johnson Foundation; 2011. http://www.rwjf.org/content/ dam/web-assets/2011/07/the-oregon-health-insurance-experiment.

20. Charmaz K. Grounded theory: Objectivist and constructivist methods. In: Denzin N, Lincoln Y, eds. Handbook of Qualitative Research. Thousand Oaks, CA: Sage Publications; 2000.

21. Boeije H. A purposeful approach to the constant comparative method in the analysis of qualitative interviews. Qual Quant. 2002; 36(4):391-409.

22. Centers for Medicare and Medicaid Services. Closing the Coverage Gap-Medicare Prescription Drugs are Becoming More Affordable. CMS Product No. 1149. Baltimore, MD: Centers for Medicare and Medicaid Services; 2012. http://www.medicare.gov/publications/pubs/ pdf/11493.pdf. Accessed Jun 1, 2012.

23. Kaiser Family Foundation. Explaining health care reform: questions about health insurance subsidies. Focus on Health Reform Report No 7962-02. Menlo Park, CA: Kaiser Family Foundation; 2010. http://www.kff.org/healthreform/upload/7962-02.pdf. Accessed Jun 1, 2012.

24. American Cancer Society Action Network. Health Reform Premium and Cost Sharing Subsidies. Washington, DC; Cancer Action Network; 2012. http://www.acscan.org/pdf/healthcare/implementation/background/HealthReformPremiumCostSharingSubsidies. pdf. Accessed Jun 1, 2012.

25. Robert Woods Johnson Foundation. Health care's blind side: the overlooked connection between social needs and good health. Summary of Findings From a Survey of America's Physicians. Princeton, NJ: Robert Wood Johnson Foundation; 2011. http://www.rwjf. org/content/dam/farm/reports/surveys_and_polls/2011/rwjf71795. Accessed Jun 1, 2012.

26. Health Leads [website]. http://www.healthleadsusa.org/. Accessed Jun 1, 2012. 